\title{
Supratentorial Brain
}

National Cancer Institute

\section{Source}

National Cancer Institute. Supratentorial Brain. NCI Thesaurus. Code C12512.

The part of the brain that is located superior to the tentorium cerebelli. 